\title{
QUASI-LEGAL BODIES OF THE MEMBER STATES OF THE EU AS PARTIES TO A PRECLUSIVE PLEA TO THE EU COURT OF JUSTICE: THE CONCEPT AND QUALIFICATION CRITERIA
}

\author{
Andrey Yu. Klyuchnikov \\ Russian Presidential Academy of National Economy and Public Administration (Lipetsk Branch), \\ Lipetsk, Russian Federation
}

\begin{abstract}
Introduction: the article deals with the status of quasi-legal bodies of the member states of the EU as parties to a preclusive plea to the EU Court of Justice, and the developed by the EU Court's case-law the criteria for the qualification of the party to the preclusive plea as a national court. The topicality of the research question is due to the fact that both at the level of EU law and the national law of the member states of the EU there is no common understanding of the party to a preclusive plea under clause 267 of Treaty on the Functioning of the European Union. Methods: the author has used the general scientific research methods such as comparison, analysis, synthesis, and the specific scientific research methods such as technical and legal and formal legal methods. Results: the author analyses the EU Court's case law in terms of the concept of «a party to a preclusive plea», determines the stages and the criteria for their legitimacy, concludes on the separateness of the concept of «court» in the European law. Conclusions: the author has found out the criteria for determining quasi-legal bodies of the EU member state, allowing it to make a preclusive plea, which are differentiated by the EU Court of Justice into the main ones (the legitimacy of the parties and their powers, the nature of their activities, the compulsory nature of their jurisdiction, the competitiveness of the procedure) and the additional ones (the party's application of the norms of law, the settlement of a dispute on the merits as one of the tasks, the lack of a higher administrative authority, the independence in decision-making), and pinpointed the problem of lack of the concept of «party to a preclusive plea» enshrined in legislation.

Keywords: European Union Court of Justice, preclusive plea, quasi-legal body, member state of the European Union, national court, qualification, authority.
\end{abstract}

УДК 341.17

ББК 67.412 .1

\section{КВАЗИСУДЕБНЫЕ ОРГАНЫ ГОСУДАРСТВ - ЧЛЕНОВ ЕС КАК СУБЫЕКТЫ ПРЕЮДИЦИАЛЬНОГО ЗАПРОСА В СУД ЕС: ПОНЯТИЕ, КРИТЕРИИ КВАЛИФИКАЦИИ}

\footnotetext{
Андрей Юрьевич Ключников

Российская академия народного хозяйства и государственной службы (Липецкий филиал), г. Липецк, Российская Федерация 


\section{МЕЖДУНАРОДНОЕ ПРАВО И СРАВНИТЕЛЬНОЕ ПРАВОВЕДЕНИЕ}

автор анализирует практику Суда ЕС относительно понятия «субъект преюдициального запроса», выделяет этапы и критерии их легитимации, делает вывод об автономности понятия «суд» в общеевропейском праве. Выводы: выявлены критерии определения квазисудебного органа государства - члена ЕС, позволяющие ему обратиться с преюдициальным запросом, которые Судом ЕС дифференцируются на основные (легитимность субъекта и его полномочий, характер его деятельности, обязательный характер его юрисдикции, состязательность производства) и дополнительные (применение субъектом норм права, разрешение спора по существу как одна из задач, отсутствие вышестоящей административной инстанции, независимость в принятии решений), определена проблема отсутствия нормативного закрепления понятия «субъект запроса».

Ключевые слова: Суд ЕС, преюдициальный запрос, квазисудебный орган, государство - член ЕС, национальный суд, квалификация, орган власти.

\section{Введение}

В результате присоединения государств к Европейскому Союзу встает вопрос о переоценке и последующем изменении прежнего понимания многих фундаментальных принципов устройства права. Деятельность всех органов власти, включая органы государственного управления, суды в их классическом конституционно-правовом смысле, должна быть подчинена принципу законности. На эти органы возложена обязанность прямого применения права ЕС при разрешении дел. Противоречащие ему или коллодирующие с ним нормы национального права не применимы.

Обеспечение эффективности права ЕС требует, чтобы в тех случаях, когда для вынесения решения по национальному делу необходимо дать толкование акта ЕC, национальный суд вправе направить преюдициальный запрос в порядке ст. 267 Договора о функционировании Европейского Союза. Эффективность обеспечивается за счет активно развивающегося сотрудничества в области правосудия и внутренних дел [3, с. 233].

Кроме того, принцип верховенства права ЕС не только обязывает государства - члены напрямую применять его положения, но и вводить в национальное право вырабатываемые практикой Суда ЕС институты, в том числе ранее существующие, но наполняемые новым содержанием по мере эволюции данного наднационального права.

Как на нормативном уровне, так и в доктрине единые подходы относительно субъектов преюдициального запроса, их квалификации в национальном праве так и не сложились, что порождает трудности на практике.

\section{Квалификация квазисудебных органов}

Подобно Европейскому суду по правам человека Суд ЕС толкует термин «суд» как субъекта запроса расширительно, включая сюда квазисудебные органы [8, с. 80], которые не являются органами национальной судебной системы.

Прежде всего, при исследовании статуса субъекта запроса Суд ЕС исходит из разграничения понятий «орган государственного управления» и «орган судебной власти». Общепринято, что компетенция органов государственного управления сводится к осуществлению текущего руководства хозяйственной, административно-политической и социальнокультурной сферами, межотраслевого управления по поручению государства в порядке исполнительной и распорядительной деятельности $[10$, с. 59], тогда как задачей судебных органов выступает отправление правосудия.

Квазисудебными органами государств членов ЕС выступают муниципальные (местные) надзорные коллегии, морские палаты, патентные ведомства, комитеты авторского права, третейские суды и арбитражи, дисциплинарные суды (дисциплинарные комиссии), иные [9, с. 162-164]. Данные субъекты характеризуются разным юридическим статусом, положением в системе органов власти и управления, характером принимаемых решений. Факт квалификации органа как квазисудебного в свете выполняемых функций и места в национальном праве не обязательно сводится к признанию его судом по смыслу ст. 267 Договора о функционировании ЕС [19].

Принципиальное отличие компетенции суда от квазисудебного органа состоит в отсутствии у последнего права на вынесение 
решения от имени государства, отсутствии инстанционной проверки, обеспечивающей законность и обоснованность судебного акта. Как отмечает М.А. Амирова, «квазисудебные органы обладают юрисдикцией, которую можно назвать обязательной, но не выносят обязательных решений» [2, с. 113]. Традиционно конституционную функцию отправления правосудия они не осуществляют, хотя в названии некоторых органов присутствуют наименования «суд» или «трибунал».

На сегодняшний день компетенция органа государственного управления не сводится исключительно к исполнению закона, на практике такие органы «подключены» к механизмам принятия законов и отправления правосудия [5, с. 44]. Управленческие задачи все чаще выполняют другие субъекты - общественные организации, предприятия, фонды, кооперативы, частные лица по отдельным направлениям, например, в сфере жилищно-коммунального хозяйства, социальной помощи. Однако такая «приватизация публичных полномочий» [7, с. 188-190] не делает их органами государственного управления, а квалификация таких органов в качестве судов-субъектов преюдициальных запросов осуществляется исключительно Судом ЕС.

Суд ЕС руководствуется собственным пониманием предметной компетенции органа власти. «В рамках конкретного дела Суд ЕС может признать в качестве суда правоприменительный орган, за которым в государстве ЕС такую компетенцию не признают» $[4$, с. 58]. Термин «суд» толкуется как автономное, в значительной степени независимое от его национальной правовой квалификации понятие.

Проблема заключается в том, что, с одной стороны, передача данного вопроса на откуп государств приведет к исключению из этой категории некоторых судов для целей права ЕС, нарушит единство наднациональной судебной практики, с другой - отрыв от национальной правовой классификации в вопросе о судебной легитимации органа государственной власти как субъекта преюдициального запроса не очевиден.

Учитывая огромное разнообразие судов, административных органов, обладающих отдельными полномочиями по судебному пра- воприменению, Суд ЕС в своих решениях последовательно вводил в практику критерии квалификации органов запроса.

\section{Критерии квалификации квазисудебных органов как субъектов преюдициального органа в Суд ЕС}

Первым в ряду таких решений было дело Ваассен-Гобельс 1966 г. [11], в котором Суд ЕС указал, что при определенных обстоятельствах в понятие «суд» могут включаться и другие учреждения, нежели общие суды. Решающее значение для квалификации не имеет ни наименование органа, ни его внутреннее устройство.

В деле Брокмюлен 1981 г. [12] Суд ЕС разъяснил, что предметному учету подлежит состав суда (определенный в силу закона или формируемый при непосредственном участии органов государственной власти), процедура (аналогичная процедуре общих судов), обязательный для сторон характер решения (не допускается в форме мнения), разрешение дела путем принятия акта по существу и его последующее исполнение, недопустимость последующего контроля со стороны других административных органов. Критерий инстанционного контроля не имеет императивный характер, поскольку его применение в каждом случае приводило бы к невозможности направления преюдициальных запросов судами нижестоящих инстанций в Суд ЕС.

Таким образом, на данном этапе во главу угла ставился вопрос правовой природы органа государственной власти, близкий к статусу суда.

В 1987 г. Суд ЕС в решении по делу ди Сало [13] уточнил приведенные критерии, указав, что принципиальное значение имеет только реализуемая органом власти при разрешении конкретного дела функция.

Начиная с решения по делу Дорш 1998 г. [14], Суд ЕС комплексно исследует правовую природу и компетенцию конкретного органа власти. В данном решении судом по смыслу права ЕС была признана немецкая Федеральная Надзорная Комиссия по государственным закупкам несмотря на то, что она напрямую подконтрольна профсоюзному Антимонопольному Бюро и структурно подчине- 


\section{МЕЖДУНАРОДНОЕ ПРАВО И СРАВНИТЕЛЬНОЕ ПРАВОВЕДЕНИЕ}

на Правительству ФРГ. Решающее значение имел тот факт, что на членов Комиссии распространялись нормы закона о порядке назначения и удаления с должности судей, гарантии их независимости и беспристрастности.

Решением 2000 г. по делу Габальфриза [15] судом был признан рассматривающий налоговые жалобы Административно-хозяйственный суд, находящийся в структуре Министерства финансов. В отличие от дела Дорш, Суд ЕС руководствовался иным подходом, указав, что поскольку данная структура была функционально отделена от выдающей административные решения государственной налоговой администрации, решения такого органа квалифицируются как судебные решения.

В практике Суда ЕС судом признавался даже комитет профессиональных организаций, действующий на основании коллективного договора как суд, чьи решения не подлежали обжалованию (решение по делу Данфосс 1989 г.) [16].

В 1999 г. Суд ЕС, признав субъектом преюдициального запроса Тирольское Управление Государственных Закупок, дополнительно разъяснил, что на такое решение не влияет отсутствие у членов органа гарантий, распространяемых на судей (дело Колендшпергер) [17].

По делу Форпоста С.А. 2012 г. [18] судом - субъектом преюдициального запроса вообще был признан классический орган управления - польская Национальная Палата Обжалования. Интересно, что в решении от 15 апреля 2014 г. Конституционный Трибунал Польши подчеркнул, что «в польской правовой системе Национальная Палата Обжалования не отвечает критериям суда в конституционно-правовом смысле, в связи с чем законодатель решил доверить контроль его решений общим судам. Решение Суда ЕC не изменило статус Палаты, не сделало ее судом или органом судебной власти по смыслу Конституции Польши» [20].

Соответственно, признание органа власти в качестве суда - субъекта преюдициального запроса не означает автоматическое его включение в судебную систему. В этой части государства - члены ЕС пользуются полной автономией.

В целом разработанные Судом ЕС критерии сводятся к определению легитимности органа власти и его полномочий (был ли орган власти создан на основании закона), характер его деятельности (не был ли созван ad hoc или действует на постоянной основе), обязательный характер его юрисдикции и состязательность производства. Указанные критерии квалификации должны присутствовать одновременно. В качестве дополнительных критериев отправления правосудия по смыслу прецедентной практики Суда ЕС выступают применение органом власти норм права, разрешение спора по существу как одна из задач, отсутствие вышестоящей «административной» инстанции, независимость в принятии решений.

Особо следует подчеркнуть, что в решении по делу Форпоста С.А. 2012 г. Суд ЕС подтвердил как актуальность ранее выработанных критериев, так и возможность «компенсации» отсутствия какого-либо критерия в каждом конкретном случае расширительным толкованием другого критерия. Применение различных критериев предполагает использование различных способов толкования.

Однако такой подход в целом порождает, на наш взгляд, проблему правовой неопределенности, не позволяет заранее сделать однозначный вывод о том, будет ли данный орган признан в качестве «национального суда». Прецедентному праву Суда ЕС в этой части свойственна значительная казуистика, критерии, сформулированные в его практике это, скорее, рекомендации, учитываемые при оценке конкретных ситуаций, нежели исчерпывающее их определение.

Согласимся с А.Х. Абашидзе, М.Н. Копыловым в том, что наднациональное право должно предлагать различные гибкие подходы для повышения дееспособности и эффективности национальных правовых систем по урегулированию различных правоотношений [1, с. 74], должны существовать дополнительные организационно-правовые и судебные гарантии обеспечения правопорядка в мире [6, с. 254].

Как представляется, Суд ЕС, приняв в качестве отправной точки автономное определение понятия «суд», с учетом разработанных критериев, и принимая во внимание огромное разнообразие национальных судов и квазисудебных органов, осуществляющих функцию правосудия, может дать исчерпыва- 
ющее его определение. На сегодняшний день такое определение отсутствует.

\section{Выводы}

Судами - субъектами преюдициального запроса в Суд ЕС выступают не только суды как органы государственной власти государств - членов ЕС, но и квазисудебные органы, обладающие отдельными признаками органа правосудия. Единый подход в ЕС к легитимации таких органов отсутствует, а Суд ЕС в каждом случае индивидуально разрешает вопрос о возможности принятия запроса к рассмотрению. Учету подлежит совокупность выработанных практикой Суда ЕС критериев, которые условно можно разделить на основные (легитимность субъекта и его полномочий, характер его деятельности, обязательный характер его юрисдикции, состязательность производства) и дополнительные (применение субъектом норм права, разрешение спора по существу как одна из задач, отсутствие вышестоящей административной инстанции, независимость в принятии решений). Отсутствие нормативного определения «квазисудебного органа как субъекта преюдициального запроса» влечет правовую неопределенность, отсутствие стабильности правоприменения на едином европейском пространстве.

\section{СПИСОК ЛИТЕРАТУРЫ}

1. Абашидзе, А. Х. Правозащитная роль современного международного права в условиях инноваций и широкого применения нанотехнологий / А. Х. Абашидзе // Вестник Волгоградского государственного университета. Серия 5, Юриспруденция. -2012 . - № 1 (16). - С. 72-78.

2. Амирова, М. А. Международные судебные учреждения и внутреннее право Российской Федерации / М. А. Амирова. - М. : ЮНИТИ-ДАНА, 2012. $-215 \mathrm{c}$.

3. Бирюков, П. Н. Международное право : в 2 т. Т. 1 : Учебник для академического бакалавриата / П. Н. Бирюков. -8 -е изд., перераб. и доп. - М. : Юрайт, 2015. - 368 с.

4. Винтер, Г. Субсидиарность и нормотворчество в рамках европейской многоуровневой системы управления / Г. Винтер // Право и политика. -2005 . - № 11. - С. 58.
5. Колоколов, Н. А. Судебная власть как общеправовой феномен : дис. ... д-ра юрид. наук / Колоколов Никита Александрович. - М. : Юрист, 2007. $-328 \mathrm{c}$.

6. Копылов, М. Н. Кодификация международного экологического права: вопросы теории и практики / М. Н. Копылов // Актуальные проблемы современного международного права : материалы ежегод. межвуз. науч.-практ. конф. каф. междунар. права, Москва, 8-9 апр. 2011 г. : в 2 ч. / отв. ред. А. Х. Абашидзе, Е. В. Киселева. - М. : Изд-во РУДН, 2012. - Ч. II. - C. 244-254.

7. Современные проблемы организации публичной власти / С. А. Авакьян [и др.] ; рук. авт. кол. и ред. С. А. Авакьян. - М. : Юстицинформ, 2014. $595 \mathrm{c}$.

8. Туманов, В. А. Автономное толкование понятий в практике Европейского Суда по правам человека / В. А. Туманов // Конституционное право: восточноевропейское обозрение. - 2003. № 3 (44). - C. 78-84.

9. Четвериков, А. О. Гарантии независимости органов правосудия интеграционных объединений современных государств: сравнительно-правовой аспект / А. О. Четвериков // Актуальные проблемы российского права. - 2015. - № 5. - С. 162-164.

10. Щукина, Т. В. Кадровая политика в системе государственной гражданской службы субъектов Российской Федерации: концептуальные подходы и административно-правовое регулирование : автореф. дис. ... д-ра юрид. наук / Щукина Татьяна Владимировна. - Воронеж, 2011. - 56 с.

11. Case C-61/65 Vaassen-Goebbels v Beambtenfonds voor het Mijnbedrijf [1966] ECR 261.

12. Case 246/80 Broekmeulen p. Huisarts Registratie Commissie [1981] ECR 02311.

13. Case C-14/86 Pretore di Salò [1987]ECR 1987.

14. Case 184/95 Dorsch Consult IngenieurgesellschaftmbH $v$ Council of the European Union and Commission of the European Communities [1998]ECR I-49.

15. Case C-147/98 Gabalfrisa SL and Others v Agencia Estatal de Administratión Tributaria [2000] ECR I-1577.

16. Case C-109/88 Danfoss [1989] ECR I-3199.

17. Case C-103/97 Kóllendsperger and Atzwanger [1999]ECR I-551.

18. Case C-465/11 Forposta SA and ABC Direct Contact sp. z o.o. v Poczta Polska SA [2012] ECR 0001.

19. The Treaty on the Functioning of the European Union // OJ C 326. - 2012. - P. 1.

20. Wyrok Trybunału Konstytucyjnego z dnia 15 kwietnia 2014 r. w sprawie o wysokość opłaty od skargi na orzeczenie Krajowej Izby Odwoławczej w postępowaniu o udzielenie zamówienia publicznego // Sygn. akt SK 12/13. 


\section{МЕЖДУНАРОДНОЕ ПРАВО И СРАВНИТЕЛЬНОЕ ПРАВОВЕДЕНИЕ}

\section{REFERENCES}

1. Abashidze A.Kh. Pravozashchitnaya rol sovremennogo mezhdunarodnogo prava v usloviyakh innovatsiy i shirokogo primeneniya nanotekhnologiy [The Human Rights' Role of the Modern International Law in the Context of Innovation and Wide Application of Nanotechnology]. Vestnik Volgogradskogo gosudarstvennogo universiteta. Seriya 5, Yurisprudentsiya [Science Journal of Volgograd State University. Jurisprudence], 2012, no. 1 (16), pp. 72-78.

2. Amirova M.A. Mezhdunarodnye sudebnye uchrezhdeniya $i$ vnutrennee pravo Rossiyskoy Federatsii [International Judicial Institutions and the Internal Law of the Russian Federation]. Moscow, UNITI-DANA Publ., 2012. 215 p.

3. Biryukov P.N. Mezhdunarodnoe pravo: $v 2 t$. T. 1: Uchebnik dlya akademicheskogo bakalavriata [International Law: in 2 vols. Vol. 1: Textbook for Academic Bachelor's Programme]. Moscow, Yurayt Publ., 2016. 368 p.

4. Vinter G. Subsidiarnost i normotvorchestvo v ramkakh evropeyskoy mnogourovnevoy sistemy upravleniya [Subsidiarity and Rule-Making in the European Multilevel System of Governance]. Pravo $i$ politika, 2005, no. 11, p. 58.

5. Kolokolov N.A. Sudebnaya vlast kak obshchepravovoy fenomen: dis. ... d-ra yurid. nauk [A Judicial Authority as a General Legal Phenomenon. Dr. jurid. sci. diss.]. Moscow, Yurist Publ., 2007. 328 p.

6. Kopylov M.N. Kodifikatsiya mezhdunarodnogo ekologicheskogo prava: voprosy teorii i praktiki [The Codification of International Environmental Law: Issues of Theory and Practice]. Abashidze A.Kh., Kiselev E.V., eds. Aktualnye problemy sovremennogo mezhdunarodnogo prava: materialy ezhegod. mezhvuz. nauch.-prakt. konf. kaf. mezhdunar. prava, Moskva, 8-9 apr. 2011 g.: v 2 ch. [Current Problems of Modern International Law: Proceedings of the Annual Interuniversity Scientific and Practical Conference of Department of International Law, Moscow, April 8-9, 2011: in 2 Parts]. Moscow, Izd-vo RUDN, 2012, Part II, pp. 244-254.

7. Avakyan S.A. Sovremennye problemy organizatsii publichnoy vlasti [Modern Problems of the Public Authority Organization]. Moscow, Ustitsinform Publ., 2014. 595 p.
8. Tumanov V.A. Avtonomnoe tolkovanie ponyatiy v praktike Evropeyskogo Suda po pravam cheloveka [Autonomous Interpretation of Concepts in the Practice of the European Court of Human Rights]. Konstitutsionnoe pravo: vostochnoevropeyskoe obozrenie, 2003, no. 3 (44), pp. 78-84.

9. Chetverikov A.O. Garantii nezavisimosti organov pravosudiya integratsionnykh obyedineniy sovremennykh gosudarstv: sravnitelno-pravovoy aspekt [The Guarantees of Independence of Court Justice Bodies of Integration Associations in Modern States]. Aktualnye problemy rossiyskogo prava, 2015, no. 5, pp. 162-164.

10. Shchyukina T.V. Kadrovaya politika $v$ sisteme gosudarstvennoy grazhdanskoy sluzhby subyektov Rossiyskoy Federatsii: kontseptualnye podkhody i administrativno-pravovoe regulirovanie: avtoref. dis. ... d-ra yurid. nauk [The Staff Policy in the System of State Civil Service in the Entities of the Russian Federation: Conceptual Approaches and Administrative-Legal Regulation]. Voronezh, 2011. $56 \mathrm{p}$.

11. Case C-61/65 Vaassen-Goebbels v Beambtenfonds voor het Mijnbedrijf [1966] ECR 261.

12. Case 246/80 Broekmeulen p. Huisarts Registratie Commissie [1981] ECR 02311.

13. Case C-14/86 Pretore di Salò [1987] ECR 1987.

14. Case 184/95 Dorsch Consult IngenieurgesellschaftmbH $v$ Council of the European Union and Commission of the European Communities [1998] ECR I-49.

15. Case C-147/98 Gabalfrisa SL and Others $v$ Agencia Estatal de Administratión Tributaria [2000] ECR I-1577.

16. Case C-109/88 Danfoss [1989] ECR I-3199.

17. Case C-103/97 Kóllendsperger and Atzwanger [1999] ECR I-551.

18. Case C-465/11 Forposta SA and ABC Direct Contact sp. z o.o. v Poczta Polska SA [2012] ECR 0001.

19. The Treaty on the Functioning of the European Union. OJC 326, 2012, p. 1.

20. Wyrok Trybunału Konstytucyjnego z dnia 15 kwietnia 2014 r. w sprawie o wysokość opłaty od skargi na orzeczenie Krajowej Izby Odwoławczej w postępowaniu o udzielenie zamówienia publicznego. Sygn. akt SK, 12/13. 
А.Ю. Ключников. Квазисудебные органы государств - членов ЕС как субъекты преюдициального запроса

\section{Information About the Author}

Andrey Yu. Klyuchnikov, Judge, Lipetsk, Pravoberzhny District Court, Plekhanova St., 72, 398050 Lipetsk, Russian Federation; Candidate of Juridical Sciences, Associate Professor, Russian Presidential Academy of National Economy and Public Administration (Lipetsk Branch), Internatsionalnaya St., 3, 398020 Lipetsk, Russian Federation, andrew19871961@mail.ru.

\section{Информация об авторе}

Андрей Юрьевич Ключников, судья Правобережного районного суда города Липецка, ул. Плеханова, 72, 398050 г. Липецк, Российская Федерация; кандидат юридических наук, доцент, Российская академия народного хозяйства и государственной службы (Липецкий филиал), ул. Интернациональная, 3, 398020 г. Липецк, Российская Федерация, andrew19871961@mail.ru. 